\title{
THE ROLE OF Zn ADDITIONS ON THE MICROSTRUCTURE AND MECHANICAL PROPERTIES OF Mg-Nd-Zn ALLOYS
}

\author{
S. Gavras ${ }^{1}$, T. Subroto ${ }^{1}$, R.H. Buzolin ${ }^{1,2}$, N. Hort ${ }^{1}$, D. Tolnai ${ }^{1}$. \\ ${ }^{1}$ Magnesium Innovation Centre, Helmholtz-Zentrum Geesthacht, Max-Planck-Straße 1, Geesthacht, Germany. \\ ${ }^{2}$ Graz University of Technology, Institute of Materials Science, Joining and Forming, Graz, Austria.
}

Keywords: Mg-Nd-Zn, phase identification, mechanical properties, synchrotron diffraction.

\begin{abstract}
Mg-rare earth alloys have improved yield strength and creep resistance compared to commercial alloys such as AZ91, AM60 or AS21. The influence of Zn additions on intermetallic phases and the resulting changes in the macroscopic mechanical behaviour of the materials, specifically $\mathrm{Mg}$ $\mathrm{Nd}$ alloys, is not yet fully understood. The aim of this work is to identify the effect of $\mathrm{Zn}$ additions on the nature of the intermetallic phases and on the mechanical properties in a $\mathrm{Mg}-4 \mathrm{Nd}$ (wt.\%) alloy. The addition of $8 \mathrm{wt} . \% \mathrm{Zn}$ to a base $\mathrm{Mg}-4 \mathrm{Nd} \mathrm{wt} . \%$ alloy marginally improved the tensile and compression properties at room temperature or at $200^{\circ} \mathrm{C}$ with the exception of the $0.2 \%$ proof stress of $\mathrm{Mg}-4 \mathrm{Nd}-8 \mathrm{Zn}$ alloys when tensile or compression tested at $200^{\circ} \mathrm{C}$. Two intermetallic phases, a quasi-binary $\mathrm{Mg}_{3}(\mathrm{Zn}, \mathrm{Nd})$ and ternary $\mathrm{Mg}_{50} \mathrm{Nd}_{8} \mathrm{Zn}_{42}$, have been identified by the means of synchrotron diffraction and electron microscopy. These results indicate that there are some discrepancies in the current thermodynamic calculations, suggesting an update to the databases may be required.
\end{abstract}

\section{Introduction}

The addition of $\mathrm{Zn}$ to $\mathrm{Mg}$-rare earth (Mg-RE) alloys has been shown to significantly improve mechanical properties including tensile and compression properties and elevated temperature creep resistance [1-4]. This means that by the addition of $\mathrm{Zn}$ to $\mathrm{Mg}-\mathrm{RE}$ alloys lower concentrations of RE additions are required to achieve similar mechanical properties compared to $\mathrm{Mg}$-RE alloys that do not have $\mathrm{Zn}$ additions. This is beneficial for the adoption of $\mathrm{Mg}-\mathrm{RE}$ alloys for industrial applications such as in the automotive industry since RE elements are relatively expensive. It has been proposed that the addition of $\mathrm{Zn}$ to $\mathrm{Mg}-\mathrm{Nd}$ alloys results in a reduction of the lattice parameter of the Mg-RE-Zn precipitates, from $\sim 0.74 \mathrm{~nm}$ to $\sim 0.72 \mathrm{~nm}$ [5]. Typically only relatively low concentrations of $\mathrm{Zn}(<1.35 \mathrm{wt} . \%)$ are required to be alloyed with $\mathrm{Mg}-\mathrm{RE}$ alloys such as $\mathrm{Mg}-\mathrm{Nd}$ in order to detect an improvement in the alloy's mechanical properties [5]. However, there is no consistent description available in the literature as to which phases are present in the $\mathrm{Mg}-\mathrm{Nd}-\mathrm{Zn}$ system [6, 7]. In the current work, a binary $\mathrm{Mg}-4 \mathrm{Nd}$ wt.\% alloy is compared with a ternary $\mathrm{Mg}-$ $4 \mathrm{Nd}-8 \mathrm{Zn}$ wt.\% in order to investigate the influence of $\mathrm{Zn}$ on the microstructure and mechanical properties. The use of such relatively high concentrations of $\mathrm{Zn}$ is used to help facilitate the formation of higher concentrations of intermetallic particles in order to assist with phase identification. 


\section{Experimental Procedure}

The two alloys under investigation in the current work were $\mathrm{Mg}-4 \mathrm{Nd}$ wt.\% and $\mathrm{Mg}-4 \mathrm{Nd}-8 \mathrm{Zn}$ wt.\%, all alloy compositions in the current work will be presented in wt.\%. The alloys were cast by permanent mould indirect chill casting producing cylinderical ingots with a length of $300 \mathrm{~mm}$ and diameter of $250 \mathrm{~mm}$ The casting process is described in greater detail elsewhere by [8]. Compositional analysis was measured via Spark-Optical Emission Spectroscopy (Spark-OES) using a Spectrolab M.

Tensile and compression samples were cut from ingots using Electron Discharge Machining (EDM). Tensile samples with a length of $60 \mathrm{~mm}$ were machined in order to have a gauge length of $35 \mathrm{~mm}$ and diameter of $6 \mathrm{~mm}$ with shoulder diameters of $9.8 \mathrm{~mm}$. Compression samples had a length of $15 \mathrm{~mm}$ and a diameter of $10 \mathrm{~mm}$. Tensile and compression tests were performed according to the DIN 50125 standard on a minimum of 5 samples per alloy and per condition. A Zwick-Z050 tensile and compression machine which has a maximum load of $50 \mathrm{kN}$ was used at room temperature and at $200^{\circ} \mathrm{C}$, using a strain rate of $10^{-3} \mathrm{~s}^{-1}$. Average grain size measurements were obtained via optical microscopy with an average of 100 grains measured per alloy using the line intercept method.

The microstructure was investigated using a TESCAN Vega3 Scanning Electron Microscope (SEM) in backscattered electron (BSE) mode. SEM samples were ground with SiC paper and polished using an oxide polishing suspension (OPS). Volume fraction analysis of intermetallic particles were determined by thresholding BSE micrographs of a minimum of 5 representative regions of the sample's microstructure. A measurement of the intermetallic (white threshold particles) was compared with the matrix (black threshold region). Characterisation of the intermetallic phases present in $\mathrm{Mg}-4 \mathrm{Nd}-8 \mathrm{Zn}$ was performed via selected area electron diffraction (SAED) on a Philips CM200 Transmission Electron Microscope (TEM) with accelerating voltage of $200 \mathrm{kV}$. TEM samples with diameter of $3 \mathrm{~mm}$ were ground to $150 \mu \mathrm{m}$ and electropolished using a $1.5 \%$ perchloric acid in ethanol solution. Bright field (BF) micrographs of the intermetallic particles were also obtained via TEM.

In situ synchrotron radiation experiments were carried out at the P07 beamline of Petra III, DESY (Deutsches Elektronen-Synchrotron). A monochromatic beam with the energy of $100 \mathrm{keV}(\lambda=$ $0.0124 \mathrm{~nm}$ ) and with a cross section of $1.1 \mathrm{~mm} \times 1.1 \mathrm{~mm}$ was used. Diffraction patterns were recorded by a PerkinElmer 1622 flat panel detector $\left(\right.$ pixel size $\left.=(200 \mu \mathrm{m})^{2}\right)$. The experiments were performed at room temperature. The morphology of the Debye-Scherrer rings was then analysed using the Fit $2 \mathrm{D}^{\circledR}$ software. The diffraction patterns were then azimuthally integrated to obtain line profiles. The Pearson's crystallographic database (Release 2015/2016) and CaRIne crystallographic software (ver. 3.1) were used to calculate the theoretical diffraction patterns. The phases were identified by comparing the line profiles and the peak position in the database. 


\section{Results and Discussion}

The compositions of the alloys used to determine tensile and compressive strength and also for microstructural analysis are shown in Table 1.

Table 1: Compositional measurements via Spark-Optical Emission Spectroscopy.

\begin{tabular}{|c|c|c|}
\hline Composition & Nd wt.\% & Zn wt.\% \\
\hline Mg-4Nd & 4.20 & 0.00086 \\
Mg-4Nd-8Zn & 4.20 & 8.00 \\
\hline
\end{tabular}

The representative stress-strain curves for the tensile tests are shown in Figure 1. The addition of $8 \mathrm{wt} . \% \mathrm{Zn}$ only marginally improved the tensile properties at room temperature (Figure 1a). This is also true for the tensile properties for the binary and ternary alloys compared at $200^{\circ} \mathrm{C}$ except for the $0.2 \%$ proof stress $\left(\sigma_{0.2}\right)$ (Figure $1 \mathrm{~b}$ ). The addition of $8 \mathrm{wt} . \% \mathrm{Zn}$ decreases the $\sigma_{0.2}$ by approximately $13 \mathrm{MPa}$ compared with the binary $\mathrm{Mg}-4 \mathrm{Nd}$ alloys when tensile tested at $200^{\circ} \mathrm{C}$ (Table 2).
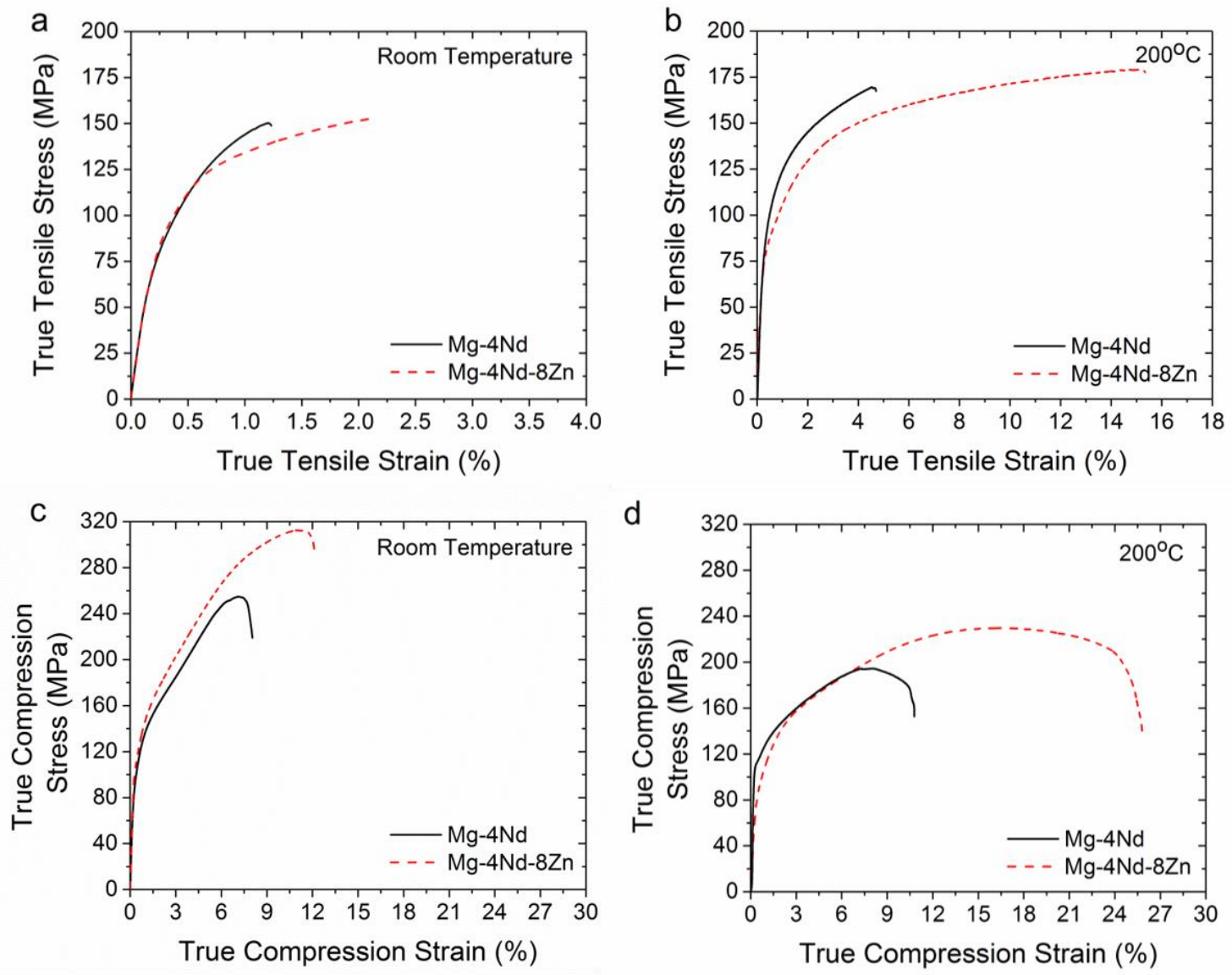

Figure 1: True stress-strain curves for $\mathrm{Mg}-4 \mathrm{Nd}$ and $\mathrm{Mg}-4 \mathrm{Nd}-8 \mathrm{Zn}$ tensile tested at a) room temperature and b) $200^{\circ} \mathrm{C}$ and compression tested at c) room temperature and d) $200^{\circ} \mathrm{C}$. 
A similar trend to the tensile properties is shown in relation to the compressive properties of $\mathrm{Mg}$ $4 \mathrm{Nd}$ and $\mathrm{Mg}-4 \mathrm{Nd}-8 \mathrm{Zn}$ (Figure 1c-d). There is a marginal improvement to the compression properties following the addition of $8 \mathrm{wt} . \%$ with the exception of the $\sigma_{0.2}$ of the $\mathrm{Mg}-4 \mathrm{Nd}-8 \mathrm{Zn}$ alloy tested at $200^{\circ} \mathrm{C}$ in comparison to the $\mathrm{Mg}-4 \mathrm{Nd}$ alloy. At both room temperature and $200^{\circ} \mathrm{C}$ compression testing the addition of $8 \mathrm{wt} . \% \mathrm{Zn}$ improves all compression properties except for the compressive $\sigma_{0.2}$ of $\mathrm{Mg}-4 \mathrm{Nd}-8 \mathrm{Zn}$ at $200^{\circ} \mathrm{C}$. The addition of $8 \mathrm{wt} . \% \mathrm{Zn}$ decreases the compressive $\sigma_{0.2}$ by approximately $10 \mathrm{MPa}$ compared with the binary Mg-4Nd alloy (Table 2).

Table 2: Average tensile and compression properties of $\mathrm{Mg}-4 \mathrm{Nd}$ and $\mathrm{Mg}-4 \mathrm{Nd}-8 \mathrm{Zn}$ at room temperature and $200^{\circ} \mathrm{C}$.

\begin{tabular}{|l|l|l|l|l|}
\hline \multicolumn{5}{|c|}{ Average Tensile Properties } \\
\hline Alloy (wt.\%) & Test Temperature & \multicolumn{1}{|c|}{$\begin{array}{c}\sigma_{0.2} \pm \text { SD } \\
(\mathrm{MPa})\end{array}$} & $\begin{array}{c}\text { UTS } \pm \text { SD } \\
(\mathrm{MPa})\end{array}$ & $\begin{array}{c}\text { Elong. }(\%) \\
\pm \text { SD }(\mathrm{MPa})\end{array}$ \\
\hline Mg-4Nd & Room Temp. & $103.4( \pm 1.8)$ & $147.7( \pm 17.0)$ & $1.2( \pm 0.3)$ \\
Mg-4Nd-8Zn & Room Temp. & $105.1( \pm 1.9)$ & $151.4( \pm 2.1)$ & $2.0( \pm 0.1)$ \\
Mg-4Nd & $200^{\circ} \mathrm{C}$ & $96.8( \pm 2.1)$ & $169.3( \pm 12.1)$ & $4.9( \pm 1.3)$ \\
Mg-4Nd-8Zn & $200^{\circ} \mathrm{C}$ & $83.9( \pm 3.2)$ & $177.7( \pm 4.7)$ & $15.2( \pm 0.5)$ \\
\hline \multicolumn{5}{|c|}{ Average Compression Properties } \\
\hline Alloy (wt.\%) & Test Temperature & \multicolumn{1}{|c|}{$\sigma_{0.2} \pm$ SD } & UCS \pm SD & Comp. $(\%)$ \\
& Room Temp. & $103.2( \pm 5.0)$ & $257.4( \pm 11.3)$ & $8.3( \pm 0.7)$ \\
\hline Mg-4Nd & $115.0( \pm 1.6)$ & $311.9( \pm 4.4)$ & $13.0( \pm 1.7)$ \\
Mg-4Nd-8Zn & Room Temp. & $99.5( \pm 7.1)$ & $198.8( \pm 13.1)$ & $10.2( \pm 1.0)$ \\
Mg-4Nd & $200^{\circ} \mathrm{C}$ & $89.0( \pm 0.4)$ & $230.1( \pm 0.3)$ & $26.4( \pm 1.0)$ \\
Mg-4Nd-8Zn & $200^{\circ} \mathrm{C}$ &
\end{tabular}

BSE micrographs are shown in Figure 2 highlighting the morphology and distribution of the intermetallic phases present in each alloy. The morphology of the intermetallic phase present in $\mathrm{Mg}-4 \mathrm{Nd}$ is continuous while for the $\mathrm{Mg}-4 \mathrm{Nd}-8 \mathrm{Zn}$ alloy there are two distinct intermetallic morphologies present, a semi-continuous intermetallic and a lamellar intermetallic phase. The increased elongation and compression properties of the $\mathrm{Mg}-4 \mathrm{Nd}-8 \mathrm{Zn}$ is likely related to the difference of intermetallic morphology between the two alloys. The combination of a semicontinuous intermetallic morphology and a lamellar eutectic morphology may inhibit the propagation of cracks through the interdendritic regions of the alloys. This would be less likely to occur in $\mathrm{Mg}-4 \mathrm{Nd}$ since it has a single, more continuous intermetallic morphology at the interdendritic regions, which facilitates crack propagation more easily than in the $\mathrm{Mg}-4 \mathrm{Nd}-8 \mathrm{Zn}$ alloy (Figure 2).

The average grain size of $\mathrm{Mg}-4 \mathrm{Nd}$ is larger than $\mathrm{Mg}-4 \mathrm{Nd}-8 \mathrm{Zn}$ and there is an expected increase in volume fraction of intermetallic from $\mathrm{Mg}-4 \mathrm{Nd}$ to $\mathrm{Mg}-4 \mathrm{Nd}-8 \mathrm{Zn}$ (Table 3). 
Table 3: Average grain size and volume fraction of intermetallic particles present in $\mathrm{Mg}-4 \mathrm{Nd}$ and Mg-4Nd-8Zn.

\begin{tabular}{|l|c|c|}
\hline Alloy (wt.\%) & Ave. Grain Size (mm) \pm SD & Ave. Vol. Frac. (\%) Intermetallic \pm SD \\
\hline Mg-4Nd & $0.36 \pm 0.02$ & $13.4 \pm 0.4$ \\
Mg-4Nd-8Zn & $0.20 \pm 0.02$ & $15.2 \pm 0.7$ \\
\hline
\end{tabular}

The intermetallic phase present in the binary $\mathrm{Mg}-\mathrm{Nd}$ alloys has been shown to be $\mathrm{Mg}_{12} \mathrm{Nd}[9,10]$. $\mathrm{Mg}-\mathrm{Nd}$ hydrides [11] can also be observed in the binary $\mathrm{Mg}-4 \mathrm{Nd}$ alloy as relatively small white features (as observed in SEM BSE) predominantly near the intermetallic/ $\alpha$-matrix boundary (Figure 2b). The Mg-4Nd-8Zn has a lamellar eutectic and a semi-continuous intermetallic phase present at the dendrite boundaries.

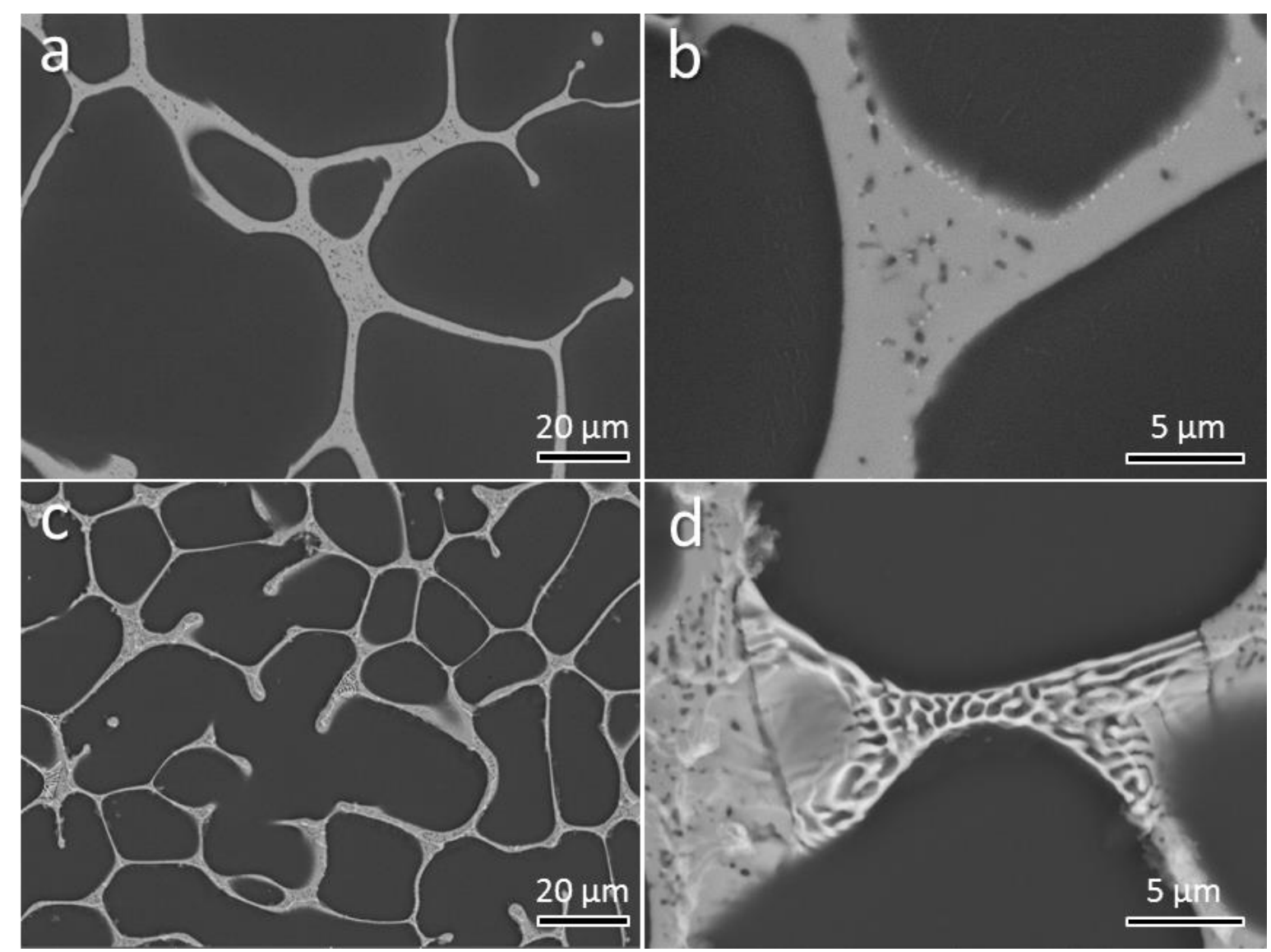

Figure 2: Backscattered electron micrographs of as-cast a-b) Mg-4Nd and c-d) Mg-4Nd-8Zn.

In order to identify if the intermetallic particles in $\mathrm{Mg}-4 \mathrm{Nd}-8 \mathrm{Zn}$ with differing morphologies are two distinct phases TEM diffraction analysis is performed. Figure 3 shows bright field TEM micrographs of the semi-continuous (Figure 3a) and the lamellar intermetallic particles (Figure 3b) with their corresponding SAED patterns. Following diffraction pattern analysis the semi- 
continuous intermetallic is characterised as a c-centred orthorhombic ternary phase, $\mathrm{Mg}_{50} \mathrm{Nd}_{8} \mathrm{Zn}_{42}$, while the lamellar intermetallic is face-centred cubic quasi-binary phase, $\operatorname{Mg}_{3}(\mathrm{Nd}, \mathrm{Zn})$.
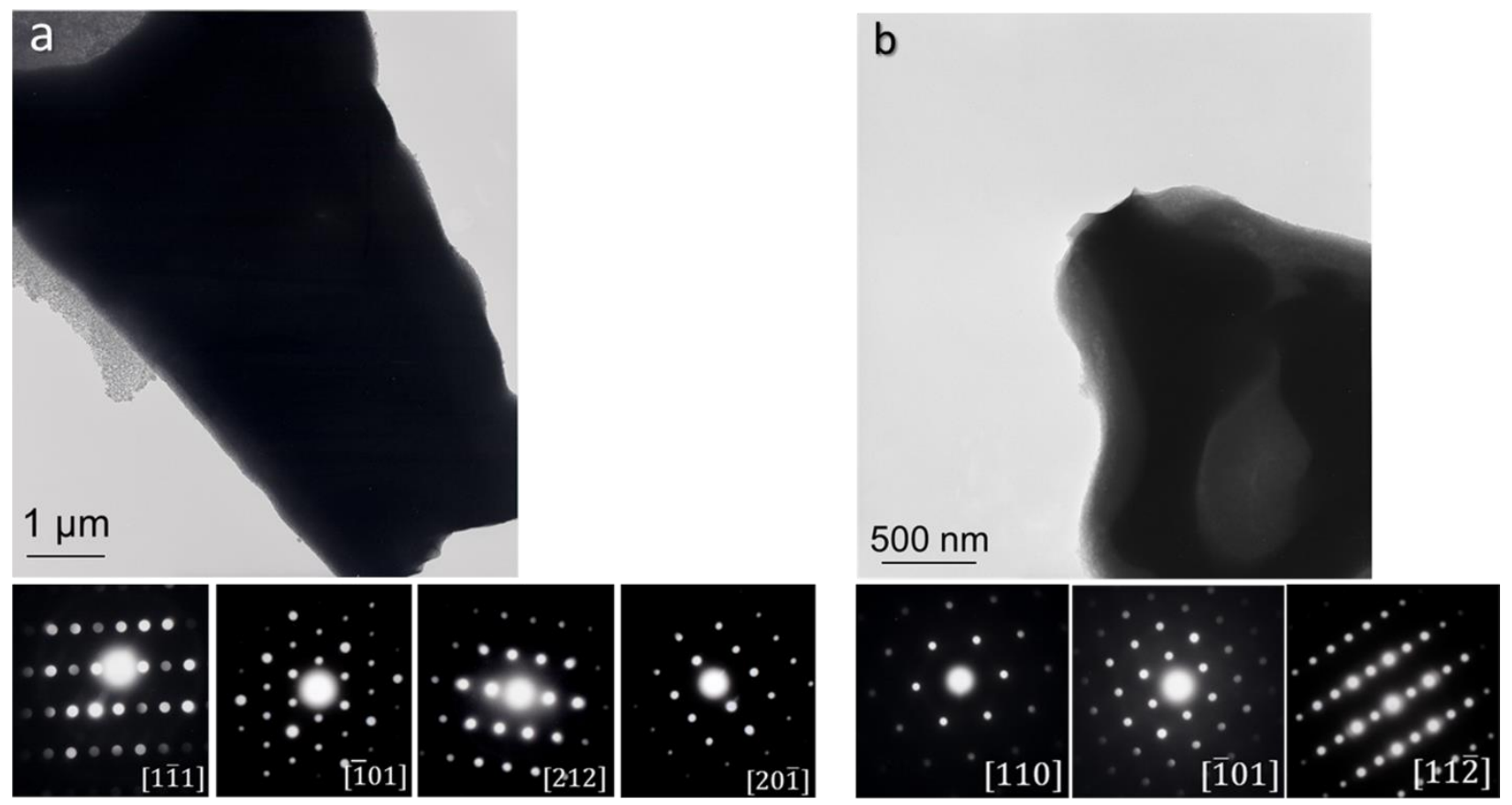

Figure 3: Bright field TEM micrographs with selected area electron diffraction patterns for a) ccentred orthorhombic and b) FCC phases present in Mg-4Nd-8Zn.

The synchrotron diffraction line profiles (Figure 4) confirm that the intermetallic present in $\mathrm{Mg}$ 4Nd alloy is $\mathrm{Mg}_{12} \mathrm{Nd}$ and in $\mathrm{Mg}-4 \mathrm{Nd}-8 \mathrm{Zn}$ are $\mathrm{Mg}_{50} \mathrm{Nd}_{8} \mathrm{Zn}_{42}$ and $\mathrm{Mg}_{3}(\mathrm{Nd}, \mathrm{Zn})$.
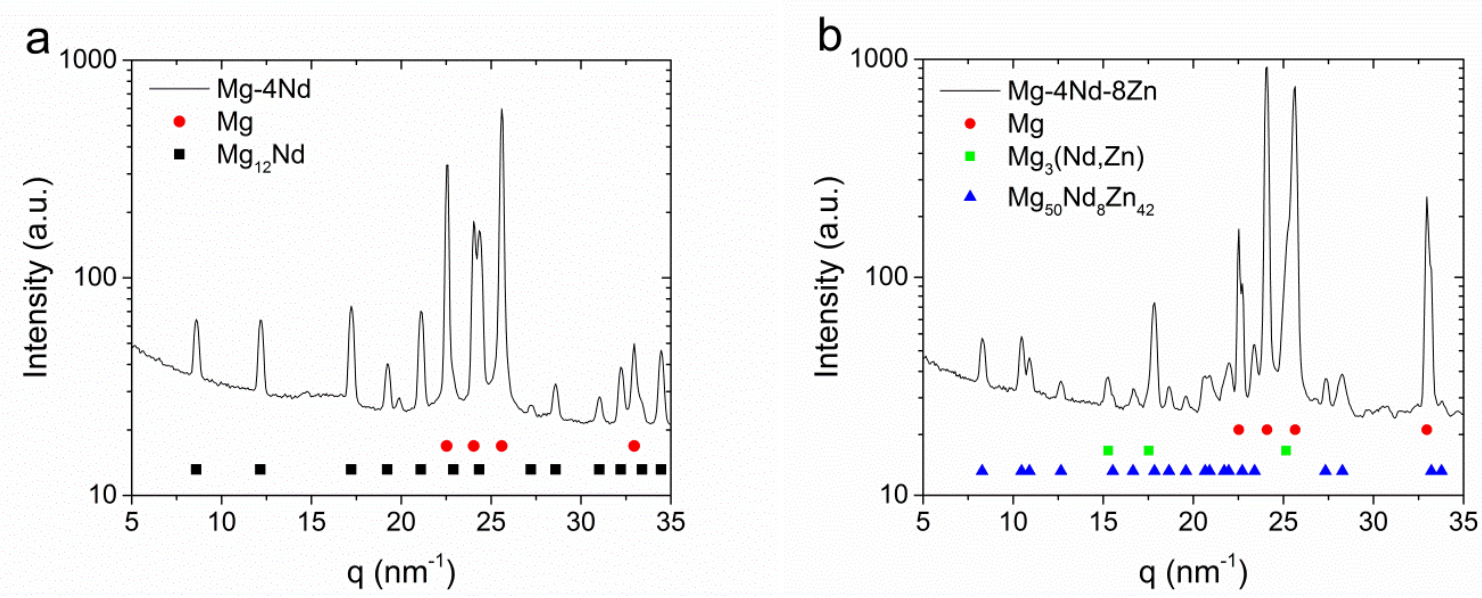

Figure 4: Synchrotron diffraction line profiles for a) Mg-4Nd and b) Mg-4Nd-8Zn.

There is however some disagreement between the results of the confirmed phases as identified by TEM diffraction analysis and the synchrotron diffraction line profiles in the Mg-4Nd-8Zn alloy with the currently accepted $\mathrm{Mg}-\mathrm{Nd}-\mathrm{Zn}$ ternary phase diagram. In the quasi-binary phase diagram 
of the $\mathrm{Mg}-\mathrm{Nd}-\mathrm{Zn}$ system at 4 wt. $\% \mathrm{Nd}$ only one intermetallic phase $\mathrm{Mg}_{50} \mathrm{Nd}_{8} \mathrm{Zn}_{42}$ and $\alpha-\mathrm{Mg}$ are shown to be present upon solidification at concentrations of $8 \mathrm{wt} . \% \mathrm{Nd}$ (Figure 5). Both the TEM analysis and synchrotron diffraction analysis clearly indicate that a quasi-binary $\mathrm{Mg}_{3}(\mathrm{Zn}, \mathrm{Nd}) \mathrm{FCC}$ phase forms at dendrite boundaries in addition to the c-centred orthorhombic phase $\mathrm{Mg}_{50} \mathrm{Nd}_{8} \mathrm{Zn}_{42}$.

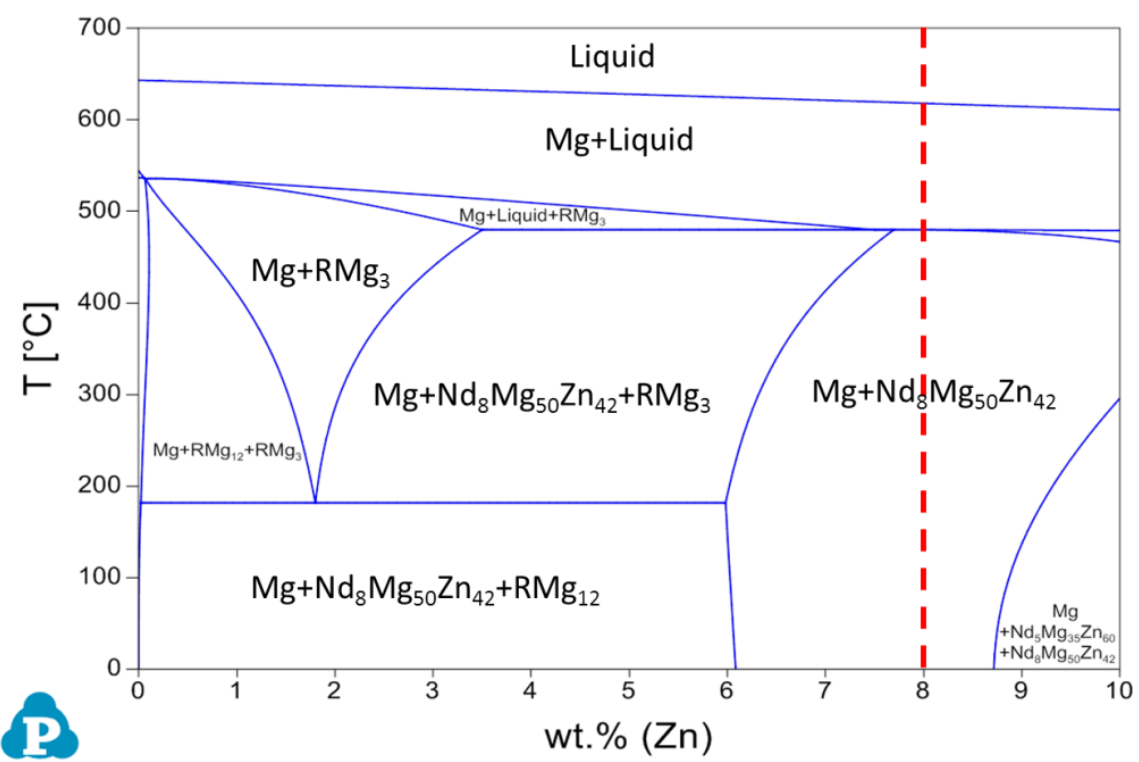

Figure 5: Quasi-binary phase diagram section of the Mg-Nd-Zn system at 4 wt.\% Nd. The dashed line indicates the region of interest for the $\mathrm{Mg}-4 \mathrm{Nd}-8 \mathrm{Zn}$ alloy.

In previous investigations by Huang et al. [6], Xu et al. [7] and Pelton et al. [12] some inconsistencies between the stated phases in the $\mathrm{Mg}-\mathrm{Nd}-\mathrm{Zn}$ system are present. In the current work it is demonstrated that corrections to the existing ternary phase diagram of the $\mathrm{Mg}-\mathrm{Nd}-\mathrm{Zn}$ system are required. Further work with various concentrations of $\mathrm{Zn}$ is currently in progress which will help to confirm if any additional corrections are required.

\section{Conclusions}

The addition of $8 \mathrm{wt} . \% \mathrm{Zn}$ to a base $\mathrm{Mg}-4 \mathrm{Nd}$ wt.\% alloy marginally improved the tensile and compression properties at room temperature or at $200^{\circ} \mathrm{C}$ with the exception of $\sigma_{0.2}$ of $\mathrm{Mg}-4 \mathrm{Nd}$ $8 \mathrm{Zn}$ alloys when tensile or compression tested at $200^{\circ} \mathrm{C}$. The addition of the relatively high concentration of $\mathrm{Zn}$ to the base $\mathrm{Mg}-4 \mathrm{Nd}$ alloy allowed for the identification of two intermetallic phases, a quasi-binary face centred cubic $\mathrm{Mg}_{3}(\mathrm{Zn}, \mathrm{Nd})$ phase and a ternary c-centred orthorhombic $\mathrm{Mg}_{50} \mathrm{Nd}_{8} \mathrm{Zn}_{42}$ phase. This result does not agree with the current ternary phase diagram for the $\mathrm{Mg}-$ $\mathrm{Nd}-\mathrm{Zn}$ system which indicates that only a single intermetallic ternary phase should be present in a $\mathrm{Mg}-4 \mathrm{Nd}-8 \mathrm{Zn}$ alloy. Investigations into $\mathrm{Mg}-4 \mathrm{Nd}-\mathrm{xZn}$ alloys will be conducted in order to further investigate the $\mathrm{Mg}-\mathrm{Nd}-\mathrm{Zn}$ ternary phase diagram. 


\section{Acknowledgements}

The authors acknowledge the Deutsches Elektronen-Synchrotron for the provision of facilities within the framework of the Proposal I-20150471 and the Deutsche Forschungsgemeinschaft for the funding in the framework of the Proposals TO817/4- 1 and ME4487/1-1.

\section{References}

[1] D. Choudhuri, D. Jaeger, M.A. Gibson, and R. Banerjee, Scripta Materialia, Vol. 86, p. 32 (2014).

[2] C.J. Bettles, M.A. Gibson, and S.M. Zhu, Materials Science and Engineering A, Vol. A505, p. 6 (2009).

[3] M.A. Gibson, M. Easton, V. Tyagi, M. Murray, and G. Dunlop: Magnesium Technology, (2008), p. 227.

[4] Magnesium elektron datasheet 463.

[5] J.F. Nie, Metallurgical and Materials Transactions A: Physical Metallurgy and Materials Science, Vol. 43A, p. 3891 (2012).

[6] M. Huang, H. Li, H. Ding, Z. Tang, R. Mei, H. Zhou, R. Ren, and S. Hao, Journal of Alloys and Compounds, Vol. 489, p. 620 (2010).

[7] H. Xu, J. Fan, H.-L. Chen, R. Schmid-Fetzer, F. Zhang, Y. Wang, Q. Gao, and T. Zhou, Journal of Alloys and Compounds, Vol. 603, p. 100 (2014).

[8] F.R. Elsayed, N. Hort, M.A. Salgado Ordorica, and K.U. Kainer: Materials Science Forum. Trans Tech Publ, (2011), p. 65.

[9] D. Tolnai, C. Mendis, A. Stark, G. Szakács, B. Wiese, K. Kainer, and N. Hort, Materials Letters, Vol. 102, p. 62 (2013).

[10] M.A. Easton, M.A. Gibson, D. Qiu, S.M. Zhu, J. Gröbner, R. Schmid-Fetzer, J.F. Nie, and M.X. Zhang, Acta Materialia, Vol. 60, p. 4420 (2012).

[11] S. Zhu, J. Nie, M. Gibson, and M. Easton, Scripta Materialia, Vol. 77, p. 21 (2014).

[12] Z. Zhu, M.A. Gharghouri, and A.D. Pelton, The Journal of Chemical Thermodynamics, Vol. 94, p. 43 (2016). 